\title{
Cupping Therapy as an Anti-inflammation Therapy and Immunomodulator in Cancer Patients
}

\author{
Nooshin Abbasi ${ }^{1,2} \cdot$ Rezvan Najafi ${ }^{1}$ (D)
}

Accepted: 23 August 2021

○) Springer Science+Business Media, LLC, part of Springer Nature 2021

Inflammation plays a pivotal role in tumor initiation, promotion, malignant conversion, invasion, and metastasis. An inflammatory microenvironment is an essential component to almost all tumors. Different forms of chronic inflammation, classifying by cause, mechanism, outcome, and intensity, are known as risk factors to cause cancer [1]. Epidemiological and molecular studies have demonstrated that chronic, persistent, and unresolved inflammation predisposes individuals to almost $20 \%$ of cancers including microbial infections in gastric cancer and gastric mucosal lymphoma, inflammatory conditions of unknown origin in prostate cancer, exposure to irritants, and autoimmune disease in colon cancer, which is a type of chronic inflammation caused by immune deregulation and autoimmunity [2-4]. Tumor and immune cells secrete inflammatory mediators such as cytokines and chemokines within the tumor microenvironment; these mediators stimulate the epithelial to mesenchymal transition (EMT) and metastasis [5, 6]. Inhibiting or modifying tumor cytokine network and signaling may result in a systematic or tumor-specific therapeutic effects [7].

Cupping therapy, as an old medical therapy, has been mentioned by Herodotus (a Greek historian, 400 BC) and Hippocrates in their prescriptions and in the Egyptian Papyrus Ebers (1550 BC) to cure different pathological conditions such as headaches, lack of appetite, maldigestion, fainting, abscess evacuation, narcolepsy musculoskeletal diseases, gynecological complaints, pharyngitis, ear ailments, and lung diseases [8]. Under different pathological conditions, the cups are placed on different parts

Rezvan Najafi

re.najafi@umsha.ac.ir; najafi2353@gmail.com

1 Molecular Medicine Research Center, Hamadan University of Medical Sciences, Shahid Fahmideh Avenue, Hamadan, Iran

2 Department of Neurosciences-DNS, University of Padua, Padua, Italy of the body skin and generally in areas of abundant muscle including back, chest, abdomen, and buttock [9].

Cupping therapy, as a neuroendocrine-immunomodulator, stimulates the body surface and makes changes in microenvironment of stimulated area through external factors, including negative pressure and cuts, and internal factors such as endogenous changes in $\mathrm{pH}$, blood flow, oxygen, secreted cytokines and neurotransmitters, and immune cell function in particular mast cell activation level [10,11].

Cupping therapy may have an anti-inflammatory and immunomodulatory effects on cancer patients.

\section{Pro- and Anti-inflammatory Lipids}

Qi Zhanga and colleagues in 2018 constructed a cupping mice model and analyzed lipid metabolism and quantified fatty acids in skin or plasma of nude mice before and after applying wet cupping therapy. They assessed the regulatory effects of wet cupping therapy on the polyunsaturated fatty acids (PUFAs) metabololipidome. The analyses showed that wet cupping therapy could increase anti-inflammatory lipids and reduce pro-inflammatory lipids in both skin and plasma. This study identified that wet cupping therapy reduces the secretion of IL- 6 and TNF- $\alpha$ induced by lipopolysaccharide (LPS) in vivo and showed that cupping treatment modulates the metabolic balance between pro- and anti-inflammatory PUFAs [12].

\section{Th1/Th2 and Treg/Th17 Ratios}

Reza Soleimani and colleagues in an observational study on healthy individuals assessed the immunomodulatory effects of wet cupping therapy and investigated the regulatory effects of this commonly used procedure on the transcription factors of T-lymphocyte subsets and its role to reduce inflammation. They found higher Foxp3 (Treg), GATA-3 
(Th2) gene expressions, higher Foxp-3/ROR $\gamma$ t (Treg)/ (Th17) gene expression ratio, and lower Tbet/GATA-3 (Th1/ Th2) gene expression ratio after cupping treatment. A higher Treg/Th17 ratio indicates a higher immunologic tolerance, which defends body from autoimmune diseases. A lower expression of Tbet means a lower number of inflammatory cytokines produced by Th1 in the body. A lower Th1/Th2 indicates the suppression of inflammation in the body and health improvement. Their results illustrated that wet cupping therapy may treat or reduce warm inflammation symptoms by increasing Th2 and Treg cells and decreasing Th1 and Th17 [13].

Navid Sobhani et al. suggested that inhibiting the cytotoxic T-lymphocyte-associated Ag-4 (CTLA-4) eradicate cancer cells especially if this therapy does not interfere with Treg cells function in impeding autoimmunity [14]. As wet cupping therapy modifies the expression of Foxp-3 in Treg cells and induces a higher immunologic tolerance towards immune system's own antigens, it may also be interesting to verify its effect on other surface markers such as CTLA-4.

\section{Prostaglandins}

The cyclooxygenase COX-2 enzymes catalyze the conversion of arachidonic acid into prostaglandins (PGs) [15]. PGs inhibit cancer cells apoptosis, enhance cancer cell migration, and promote neoangiogenesis in stromal tissue [16]. A higher level of COX-2 is detected in breast, prostate, pancreas, skin, lung, bladder, and head and neck cancers [17-23]. Anti-inflammatory agents including NSAIDs, aspirin, and statins used to treat other diseases are seen to be effective in treatment of cancer [7].

Cupping therapy may also be seen as a novel method to excrete PGs from the blood capillaries. The negative pressure created into the cup, from 150 to $420 \mathrm{mmHg}$, and the scratches made with scalpel stimulate innate immune system, inflammatory cell migration, and endogenous opioid release [24]. The suction increases blood volume under the cup area and increases capillary filtration rate. When the cuts are applied, the negative pressure excretes prostaglandins and inflammatory mediators from the blood and interstitial fluid. Cupping therapy improves blood flow, oxygen supply, and tissue perfusion [25].

A randomized clinical trial on sixty-six patients assessed the effects of wet cupping therapy to reduce pressure and pain and to improve joint movements in acute scapulohumeral periarthritis. They tested 5-hydroxy-tryptamine (5-HT) and prostaglandin $\mathrm{E}_{2}\left(\mathrm{PGE}_{2}\right)$ of blood in the cups and demonstrated the excretion of these inflammatory substances in local blood of the affected shoulder through wet cupping therapy. They showed a decrease in 5-HT and $\mathrm{PGE}_{2}$ in the body and an improvement in pain and shoulder movements after applying EA [26].

\section{Conclusion}

Similar to anti-inflammatory drugs, cupping therapy may be seen as an adjuvant therapeutic strategy to modulate host microenvironment by reducing inflammation and modulating immune system, all actions that could be useful in biological treatments, in cancer patients. However, the exact mechanism of action of this ancient therapeutic method is not fully understood yet but we hypothesize that cupping therapy may improve the efficacy of conventional therapeutics and immunotherapies by preventing or delaying cancer onset. We suggest that scientists and clinicians assess the therapeutic effects of cupping therapy as adjuvant treatment along with other therapeutic strategies in treatment of cancer.

Author Contribution All authors contributed to the study conception and design. All authors reviewed this draft, contributed, and approved the final manuscript.

\section{Declarations}

Research Involving Human Participants and/or Animals Not applicable.

Consent for Publication All the authors approved the present version for publication purposes and agreed to hold accountability for all aspects of the work.

Informed Consent Not applicable.

Conflict of Interest The authors declare no competing interests.

\section{References}

1. Grivennikov SI, Greten FR, Karin M. Immunity, inflammation, and cancer. Cell. 2010;140(6):883-99. https://doi.org/10.1016/j. cell.2010.01.025.

2. Kundu JK, Surh YJ. Inflammation: gearing the journey to cancer. Mutat Res. 2008;659(1-2):15-30. https://doi.org/10.1016/j.mrrev. 2008.03.002.

3. Mantovani A, Allavena P, Sica A, Balkwill F. Cancer-related inflammation. Nature. 2008;454(7203):436-44. https://doi.org/ 10.1038/nature07205.

4. Waldner MJ, Neurath MF. Colitis-associated cancer: the role of $\mathrm{T}$ cells in tumor development. Semin Immunopathol. 2009;31(2):249-56. https://doi.org/10.1007/s00281-009-0161-8.

5. Germano G, Allavena P, Mantovani A. Cytokines as a key component of cancer-related inflammation. Cytokine. 2008;43(3):374-9. https://doi.org/10.1016/j.cyto.2008.07.014.

6. Hanahan D, Coussens LM. Accessories to the crime: functions of cells recruited to the tumor microenvironment. Cancer Cell. 2012;21(3):309-22. https://doi.org/10.1016/j.ccr.2012.02.022. 
7. Crusz SM, Balkwill FR. Inflammation and cancer: advances and new agents. Nat Rev Clin Oncol. 2015;12(10):584-96. https://doi. org/10.1038/nrclinonc.2015.105.

8. Turk JL, Allen E. Bleeding and cupping. Ann R Coll Surg Engl. 1983;65(2):128-31.

9. Yoo SS, Tausk F. Cupping: East meets West. Int J Dermatol. 2004;43(9):664-5. https://doi.org/10.1111/j.1365-4632.2004. 02224.X.

10. Tian YY, Wang GJ, Huang T, Jia SY, Zhang YQ, Zhang WB. Impacts on skin blood flow under moving cupping along meridians in different directions. Zhongguo Zhen Jiu. 2013;33(3):247-51.

11. Li T, Li Y, Lin Y, Li K. Significant and sustaining elevation of blood oxygen induced by Chinese cupping therapy as assessed by near-infrared spectroscopy. Biomed Opt Express. 2017;8(1):2239. https://doi.org/10.1364/BOE.8.000223.

12. Zhang Q, Li Y. Anti- versus pro-inflammatory metabololipidome upon cupping treatment. European Journal of Immunology. 2019;49:1307.

13. Soleimani R, Mohammadi M, Saghebi SA, Taghipour A, Khorsand Vakilzadeh A, Tavakkol AJ. Comparison of Th1/Th2 and Treg/Th17 ratios between wet and dry cupping therapies in Persian medicine. Avicenna J Phytomed. 2020;10(1):24-34.

14. Sobhani N, Tardiel-Cyril DR, Davtyan A, Generali D, Roudi R, Li Y. CTLA-4 in regulatory T cells for cancer immunotherapy. Cancers. 2021;13(6):1440.

15. Nørregaard R, Kwon TH, Frøkiær J. Physiology and pathophysiology of cyclooxygenase-2 and prostaglandin E2 in the kidney. Kidney Res Clin Pract. 2015;34(4):194-200. https://doi.org/10. 1016/j.krcp.2015.10.004.

16. Masferrer JL, Leahy KM, Koki AT, Zweifel BS, Settle SL, Woerner BM, et al. Antiangiogenic and antitumor activities of cyclooxygenase-2 inhibitors. Cancer Res. 2000;60(5):1306-11.

17. Hwang D, Scollard D, Byrne J, Levine E. Expression of cyclooxygenase-1 and cyclooxygenase- 2 in human breast cancer. J Natl Cancer Inst. 1998;90(6):455-60. https://doi.org/10.1093/jnci/90.6. 455 .

18. Gupta S, Srivastava M, Ahmad N, Bostwick DG, Mukhtar H. Over-expression of cyclooxygenase-2 in human prostate adenocarcinoma. Prostate. 2000;42(1):73-8. https://doi.org/10.1002/(sici) 1097-0045(20000101)42:1\%3c73::aid-pros9\%3e3.0.co;2-g.
19. Tucker ON, Dannenberg AJ, Yang EK, Zhang F, Teng L, Daly $\mathrm{JM}$, et al. Cyclooxygenase-2 expression is up-regulated in human pancreatic cancer. Cancer Res. 1999;59(5):987-90.

20. Buckman SY, Gresham A, Hale P, Hruza G, Anast J, Masferrer J, et al. COX-2 expression is induced by UVB exposure in human skin: implications for the development of skin cancer. Carcinogenesis. 1998;19(5):723-9. https://doi.org/10.1093/carcin/19.5.723.

21. Wolff H, Saukkonen K, Anttila S, Karjalainen A, Vainio H, Ristimäki A. Expression of cyclooxygenase-2 in human lung carcinoma. Cancer Res. 1998;58(22):4997-5001.

22. Mohammed SI, Knapp DW, Bostwick DG, Foster RS, Khan KN, Masferrer JL, et al. Expression of cyclooxygenase-2 (COX-2) in human invasive transitional cell carcinoma (TCC) of the urinary bladder. Cancer Res. 1999;59(22):5647-50.

23. Chan G, Boyle JO, Yang EK, Zhang F, Sacks PG, Shah JP, et al. Cyclooxygenase-2 expression is up-regulated in squamous cell carcinoma of the head and neck. Cancer Res. 1999;59(5):991-4.

24. El Sayed SM, Abou-Taleb A, Mahmoud HS, Baghdadi H, Maria RA, Ahmed NS, et al. Percutaneous excretion of iron and ferritin (through Al-hijamah) as a novel treatment for iron overload in beta-thalassemia major, hemochromatosis and sideroblastic anemia (vol 83, pg 238, 2014). Med Hypotheses. 2015;85(2):239-. https://doi.org/10.1016/j.mehy.2015.06.004.

25. Ghods R, Sayfouri N, Ayati MH. Anatomical features of the interscapular area where wet cupping therapy is done and its possible relation to acupuncture meridians. JAMS J Acupunct Meridian Stud. 2016;9(6):290-6. https://doi.org/10.1016/j.jams.2016.06. 004.

26. Sun H, Wan H, Zhang L, He X. Clinical observation of bloodletting to reduce pressure plus electroacupuncture for acute scapulohumeral periarthritis. Zhongguo Zhen Jiu. 2016;36(9):933-7. https://doi.org/10.13703/j.0255-2930.2016.09.010.

Publisher's Note Springer Nature remains neutral with regard to jurisdictional claims in published maps and institutional affiliations. 